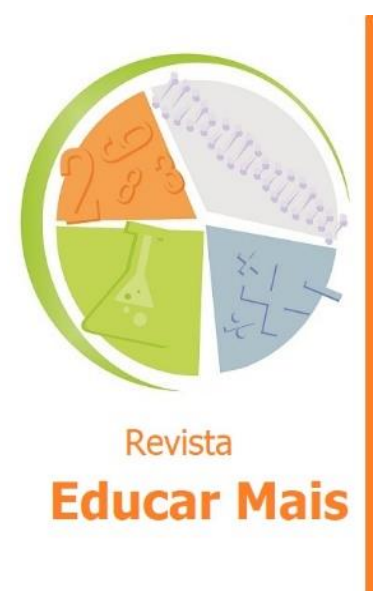

\title{
Tecnologias da informação e comunicação na educação: desafios, possibilidades e contribuições para ensino e a aprendizagem
}

\author{
Information and communication technologies in education: \\ challenges, possibilities and contributions to teaching and learning
}

Tecnologías de la información y la comunicación en educación: retos, posibilidades y contribuciones a la enseñanza y el aprendizaje

\author{
José Luis Monteiro da Conceição ${ }^{(\mathbb{D})}$; Fabricio Nicácio Ferreira2 ${ }^{(\mathbb{D})}$
}

\section{RESUMO}

No século XIX, o ensino praticado pelos professores era tecnicamente inspirado na educação tradicional. As estratégias didáticas adotadas resumiam-se em aulas expositivas, mantendo-o como detentor do conhecimento e o aluno expectador. Com o passar do tempo, esse cenário foi modificado, principalmente pele a inserção de Tecnologias da Informação e Comunicação (TIC's) no processo educativo. Contudo, ainda é perceptível a existência de empasses que devem ser superados. Neste sentido, o presente artigo tem como objetivo discutir as barreiras que impedem os professores utilizarem das TIC em suas aulas. Visa também, apresentar as contribuições que elas propiciam tanto para o aluno, quanto para o professor em benefício de uma aprendizagem integral e significativa. Assim, realizou-se um estudo bibliográfico com a sistematização de pesquisas empíricas brasileiras publicadas no período de 2016 a 2021. Constatou-se que existem barreiras que interferem na adoção das TIC no ambiente escolar, a saber: a resistência por parte do docente sobre o uso das ferramentas tecnológicas, equipamentos no ambiente escolar sucateados, falta de investimento em infraestrutura nas escolas, ausência de laboratórios de informática e falta de capacitação docente para usar a tecnologia. No entanto, foi consenso entre $100 \%$ dos estudos o quanto as TIC's contribuem efetivamente para a prática pedagógica do professor e, sobretudo na aprendizagem do aluno.

Palavras-chave: Aluno; Ensino; Educação; Professor; Tecnologia.

\begin{abstract}
In the 19th century, teacher education was technically inspired by traditional education. The didactic strategies adopted were summarized in merely expository classes, the teacher was the holder of knowledge and the student was the spectator of the class. Over time, this scenario was modified, mainly due to the insertion of new Information and Communication Technologies (ICTS) in the educational process. It is also noticeable the existence of deadlocks that must be overcome. In this sense, this article aims to discuss the barriers that prevent teachers from using ICT in their classes. It also aims to present the contributions they provide for both the student and the teacher in benefit of a comprehensive and meaningful learning. Thus, a bibliographical study was carried out with the systematization of Brazilian empirical research published in the period from 2016 to 2021. It was found that there are barriers that interfere in the adoption of ICT in the school environment, namely: resistance on the part of the teacher about the use of technological tools, scrapped equipment in the school environment, lack of investment in infrastructure in schools, lack of computer labs and lack of teacher
\end{abstract}

\footnotetext{
${ }^{1}$ Mestre em Educação, Pedagogo, Licenciado em Letras/Português e Inglês. Instituto de Formação Educacional da Bahia (IFEB), Valença/BA - Brasil. E-mail: luisuneb1@hotmail.com

${ }^{2}$ Mestre em Desenvolvimento e Meio Ambiente, Especialista em Gestão Estratégica da Saúde da Família e Licenciado em Biologia. Instituto de Formação Educacional da Bahia (IFEB), Valença/BA - Brasil. E-mail: nicacioassessoria@gmail.com
} 
training to use technology. However, there was a consensus among $100 \%$ of the studies how much ICT's effectively contribute to the teacher's pedagogical practice and, above all, in the student's learning.

Keywords: Student; Teaching; Education; Teacher; Technology.

\section{RESUMEN}

En el siglo XIX, la formación del profesorado se inspiró técnicamente en la educación tradicional. Las estrategias didácticas adoptadas se resumieron en clases meramente expositivas, el docente era el poseedor del conocimiento y el alumno era el espectador de la clase. Con el tiempo, este escenario se fue modificando, principalmente por la inserción de las nuevas Tecnologías de la Información y la Comunicación (TIC) en el proceso educativo. Todavía se nota la existencia de puntos muertos que deben superarse. En este sentido, este artículo tiene como objetivo discutir las barreras que impiden que los docentes utilicen las TIC en sus clases. También tiene como objetivo presentar los aportes que brindan tanto al alumno como al docente en beneficio de un aprendizaje integral y significativo. Así, se realizó un estudio bibliográfico con la sistematización de la investigación empírica brasileña publicada en el período de 2016 a 202. Se encontró que existen barreras que interfieren en la adopción de las TIC en el ámbito escolar, a saber: resistencias por parte del docente sobre el uso de herramientas tecnológicas, equipamiento desguazado en el entorno escolar, falta de inversión en infraestructura en las escuelas, falta de laboratorios de computación y falta de capacitación docente para el uso de la tecnología. Sin embargo, hubo consenso entre el 100\% de los estudios sobre cuánto contribuyen efectivamente las TIC a la práctica pedagógica del docente y, sobre todo, al aprendizaje del alumno.

Palabras clave: Alumno; Enseñando; Educación; Maestro; Tecnología.

\section{INTRODUÇÃO}

Tecnologia da Informação e Comunicação (TIC) pode ser definida como um conjunto de recursos tecnológicos, que serve como mediadora para o processo de comunicação. É utilizada de forma integrada, com um objetivo comum. Encontramos nas mais diversas formas, seja ela na indústria no que se refere ao processo de automação, no setor de comércio no que tange gerenciamento, nas diversas formas de publicidade e na educação, este relacionado ao processo de ensino aprendizagem.

A tecnologia tem possibilidade de revolucionar à nossa maneira de agir, pensar, de viver, relacionarnos com outras pessoas e, com a educação, e nos espaços escolares não é diferente. Ela contribui tanto para a prática pedagógica e metodológica do professor (ensino), quanto para o desenvolvimento e (re)construção do saber do aluno (aprendizagem).

A implementação de tecnologias da informação e comunicação (TIC) em sala de aula caracteriza-se como um desafio a ser superado e uma inovação pertinente ao avanço nas práticas educacionais. É evidente em nosso século o interesse de muitos em permanecer com métodos de ensino tradicionais pautados apenas em aulas explicativas e expositivas, com o uso de quadro e giz. Entretanto é preciso repensar essas práticas que ainda se encontram intrínsecas em muitos docentes para que se possa construir saberes significativos com a inclusão instrumentos tecnológicos que são vivenciados no cotidiano discente (BATISTA; ANDRADE, 2020).

Por muito tempo a nossa educação, mais precisamente a partir do século XIX desenvolvia o seu fazer pedagógico inspirado no método de ensino tradicional. Nesta forma didática e técnica de ensinar, o professor era considerado o detentor e o sujeito principal do conhecimento. Este, por sua vez, tinha o intuito de "repassar e/ou transmitir o conteúdo" que era apresentado por aulas expositivas. Limitava-se basicamente aos livros e quadro de giz, não permitia intervenção e contribuições dos 
alunos. Este último, sendo objeto do ensino e aprendizagem, cabia apenas a memorizar e reproduzir aquilo que foi explicado pelo professor.

Para Brighente e Mesquita (2016) o autoritarismo é a palavra que define esse método didático pedagógico o qual se encontra permeado em ordenar o que o discente deve fazer e responder, não sendo possível tecer críticas ou até se questionar e duvidar do docente, esses aspectos da educação bancária.

Em contraposição a este método de ensino, o construtivismo permite aos professores utilizarem diferentes recursos tecnológicos para ajudar a dinamizar o ensino e auxiliar o aluno a aprender os objetos do conhecimento (conteúdos) de maneira fácil, dinâmica e interativa. O aluno passa a ser concebido como protagonista da sua própria aprendizagem, sujeito e parceiro do trabalho pedagógico do professor.

Com a utilização das Tecnologias de Informação e Comunicação (TICs) na sala de aula pode-se dizer que é possível disponibilizar para o aluno o desenvolvimento crítico, reflexivo e criativo assim como a aprendizagem colaborativa, ou seja, todos os sujeitos envolvidos no processo educativo trabalham de forma coletiva, em equipe e pequenos grupos (GONÇALVES et al., 2018; CAMILLO; MEDEIROS, 2018; PEREIRA, 2019).

O aparecimento das TIC's e sobretudo da internet nos espaços escolares possibilitaram a ampliação e o acesso à informação de forma inovadora e criativa causando rupturas e novas nuances com o aprender (SANTOS, 2020). Neste contexto, o professor teve o papel de mediador dos trabalhos pedagógicos o que possibilitou com que os alunos interagissem uns com os outros e contribuíssem efetivamente na prática pedagógica daquele que ensina.

Para isso o projeto pedagógico da escola deve estar condizente com as transformações que as tecnologias trouxeram. A superação de paradigmas por parte do docente é fundamental para que ocorram mudanças significativas no processo de aprendizagem. Refletir sobre suas práticas pedagógicas pautadas apenas em atitudes tradicionais fragiliza a construção do conhecimento no espaço intra e extraescolar.

Estamos na Era do Conhecimento, o processo de ensino-aprendizagem vem, paulatinamente, sendo mediado pelas TIC. Entretanto é muito comum encontrar professores despreparados para utilizar as tecnologias, além disso, desmotivados e sem demonstrar interesse em aprender sobre as tecnologias para melhorar sua prática pedagógica.

Encontramos nas instituições educacionais um número razoável de professores que estão experimentando estas novas metodologias, utilizam aplicativos atraentes e compartilham o que aprendem em rede. O que predomina, no entanto, é uma certa acomodação, repetindo fórmulas com embalagens mais atraentes, esperando receitas, num mundo que exige criatividade e capacidade de enfrentar desafios complexos. Há também um bom número de docentes e gestores que não querem mudar, que se sentem desvalorizados com a perda do papel central como transmissores de informação e que pensam que as metodologias ativas deixam o professor em um plano secundário e que as tecnologias podem tomar o seu lugar. (MORIN, 2015, p.1)

Neste sentido, o presente artigo tem como objetivo apresentar, discutir as barreiras, empecilhos que impedem que os professores utilizem as TIC's durante o processo de ensino e aprendizagem. Além disso, visa também demonstrar as contribuições tanto para o aluno, quanto para o professor da utilização dessas ferramentas em sala de aula em benefício do ensino e aprendizagem. 


\section{MATERIAIS E MÉTODOS}

Propusemos realizar em primeiro momento uma revisão bibliográfica de natureza exploratória cujo objetivo é "possibilitar um maior conhecimento a respeito do problema, de modo a torná-lo mais claro ou auxiliado na formulação de hipótese" (GIL, 2018) realizou-se a análise de artigos completos e livros que versam sobre os desafios, possibilidades e contribuições das novas tecnologias da informação e comunicação no processo de ensino e aprendizagem. Cabe salientar que esta primeira etapa reuniu as principais referências que caracterizou a amostragem da pesquisa.

Em seguida, fez-se um levantamento de pesquisas empíricas brasileiras no Banco Digital de Teses e Dissertações - BDTD sobre o objeto de estudo com a finalidade de ampliar o rol de trabalhos sobre o tema. Utilizou-se um recorte temporal de cinco anos, compreendido no período de 2016 a 2021. Para realizar está etapa no banco de dados definiu-se os seguintes descritores: "tecnologia na educação", "educação e tecnologia" "contribuição da tecnologia na educação"

No BDTD, com a palavra-chave "tecnologia na educação" foram achados no dia 01 de outubro de 2021, 514 publicações. Após a leitura dinâmica do título e dos resumos foram selecionadas para a leitura aprofundada do texto completo, 5 pesquisas acadêmicas. Já a palavra-chave "educação e tecnologia" remeteu 302 trabalhos dos quais 300 foram excluídas, restando apenas 2 pesquisas para a leitura na íntegra. Inserindo o termo "contribuição da tecnologia na educação" na plataforma, registrou 516 publicações, deste, 4 faziam referência ao objeto de estudo. Portanto, foram selecionadas 11 pesquisas empíricas brasileiras. Para a operacionalização das análises dos textos utilizou-se da proposta metodológica de Bardin (2004), ou seja, "descreve-se como uma operação de desmembramento do texto em unidades onde é possível identificar os diferentes núcleos de sentido que constituem a comunicação, e, posteriormente realizar o ser reagrupamento em classes [...]" (BARDIN, 2004, p.201).

Neste sentido, sugere-se uma análise metodológica conhecida como técnica de análise categorial. Seguindo este referencial foram adotadas para discussão deste trabalho duas categorias: a) desafios da TIC's na educação e b) Contribuições da TIC's na educação.

\section{RESULTADOS}

Nesta seção, descreve-se primeiramente os resultados da análise das bibliografias que versam sobre os principais desafios que os professores enfrentam durante o processo de ensino e aprendizagem para inserir as TIC's na educação. Neste sentido, apoiamos nos pensamentos de Batista \& Andrade (2020); Vidal; Miguel (2020); Pereira e Chagas (2014). Em seguida, tecemos uma discussão sobre as contribuições das novas tecnologias da informação e comunicação para o ensino do professor e aprendizagem do aluno na perspectiva teórica de Wiese; Silva (2016); Queiroz (2018); Batista; Andrade (2020) e apresentamos e discutimos os principais resultados de pesquisas empíricas brasileiras de 2016 a 2021 sobre o objeto de estudo conforme o quadro abaixo: 
Quadro 1. Títulos das pesquisas e respectivos autores sobre TIC

\begin{tabular}{|c|c|}
\hline TÍTULOS DAS PESQUISAS & AUTORES / ANO DE PUBLICAÇÃO \\
\hline $\begin{array}{l}\text { Leitura e produção de histórias em quadrinhos } \\
\text { digitais: uma proposta de uso do smartphone }\end{array}$ & Nice Vânia Machado Rodrigues Valadares (2019) \\
\hline $\begin{array}{l}\text { Google for education na formação continuada de } \\
\text { professores do ensino médio em Patos-PB. }\end{array}$ & Josley Maycon de Sousa Nóbrega (2018) \\
\hline $\begin{array}{l}\text { Educação e tecnologia: o uso dos dispositivos } \\
\text { móveis como auxílio no processo de ensino e } \\
\text { aprendizagem em sala de aula. }\end{array}$ & Eleine Silva Pesker (2018) \\
\hline $\begin{array}{l}\text { Tecnologia digital e dispositivos móveis como } \\
\text { facilitadores do ensino-aprendizagem de } \\
\text { ondulatória no ensino médio. }\end{array}$ & Reginaldo Almeida dos Santos (2018) \\
\hline $\begin{array}{l}\text { Integração de Tecnologia na Educação Básica: Um } \\
\text { estudo de caso nas aulas de Biologia utilizando } \\
\text { laboratórios on-line. }\end{array}$ & Aline Coêlho dos Santos (2018) \\
\hline $\begin{array}{l}\text { Contribuições das Tecnologias para uma } \\
\text { aprendizagem significativa e o desenvolvimento de } \\
\text { projeto no ensino fundamental I. }\end{array}$ & André Geraldo Cursino (2017) \\
\hline $\begin{array}{l}\text { A tecnologia como estratégia Etnomatemática: Um } \\
\text { estudo de caso sobre o uso das tecnologias no } \\
\text { ensino da Matemática no sexto ano do Ensino } \\
\text { Fundamental- Anápolis. }\end{array}$ & Claci Clair Röpke da Silva (2017) \\
\hline $\begin{array}{l}\text { O uso da tecnologia na educação infantil: } \\
\text { contribuições e implicações pedagógicas. }\end{array}$ & Paula Virginia Alves Pereira (2016) \\
\hline $\begin{array}{l}\text { Uso de tecnologias de informação no ensino } \\
\text { fundamental e o desempenho escolar no sul do } \\
\text { Brasil: o caso do tablet no município Doutor } \\
\text { Maurício Cardoso }\end{array}$ & Maicon Rafael Hammes (2016) \\
\hline $\begin{array}{l}\text { A utilização da internet nas aulas de Biologia: } \\
\text { estudo de caso em uma escola da rede estadual de } \\
\text { Alagoas }\end{array}$ & Emerson dos Santos Nascimento (2016) \\
\hline $\begin{array}{l}\text { Tecnologias de Informação e Comunicação na } \\
\text { escola: Contradições e elementos de aprendizagem }\end{array}$ & Bruno Passos Fialho (2016) \\
\hline
\end{tabular}

Fonte: Elaborado pelos autores, 2022.

Segue expressa de forma sistematizada a quantidade de produções científicas publicadas por ano.

Tabela 1. Produções científicas acerca do uso das TIC's na Educação Básica no período de 2016 a 2021.

\begin{tabular}{ccc}
\hline ANO & DISSERTAÇÕES & TESES \\
\hline $\mathbf{2 0 1 6}$ & 04 & 00 \\
$\mathbf{2 0 1 7}$ & 02 & 00 \\
$\mathbf{2 0 1 8}$ & 04 & 00 \\
$\mathbf{2 0 1 9}$ & 01 & 00 \\
$\mathbf{2 0 2 0}$ & 00 & 00 \\
$\mathbf{2 0 2 1}$ & 00 & 00 \\
TOTAL & 11 & 00 \\
\hline
\end{tabular}

Fonte: Biblioteca Digital Brasileira de Teses e Dissertações, acessado no período de 01/10/2021 e elaborado pelos autores em 2021. 
Nota-se que em 2016 houve 4 publicações científicas, especificamente dissertações de mestrado. No ano de 2017, houve uma queda de publicação que tratavam sobre as contribuições da Tecnologia da Informação e Comunicação para o ensino do professor e aprendizagem do aluno, registrando 2 pesquisas. Voltou a crescer em 2018 com 4 publicações, mantendo o mesmo número quantitativo do ano de 2016. Entretanto, em 2019 o número de publicação caiu mais da metade, ou seja, houve apenas 1 publicação. Salienta-se aqui, que não se obteve registros de teses que tratassem acerca do tema proposto.

Fato preocupante haja vista que a produção científica frente a esta temática nos revela os caminhos percorridos, os desafios que ainda existem e os passos a serem dados para que ocorra a materialização e adoção dessa nova forma de estratégia didática em sala de aula.

\section{DISCUSSÕES}

\subsection{Desafios das TIC's na educação}

A escola tem percebido a contribuição das tecnologias para o desenvolvimento da aprendizagem do aluno. Sabe também o quão é importante para a dinamização do trabalho docente, sobretudo com a finalidade de atrair a atenção dos alunos. Diante disso, Batista \& Andrade (2020) tecem que:

No mundo contemporâneo em que conhecimento e tecnologia estão incorporados em todas as relações sociais torna-se quase que impossível a instituição escolar esquivarse desse contexto. Adequar-se às novas necessidades da sociedade tecnológica e digital é o grande desafio da educação para assim, possibilitar aos sujeitos à compreensão crítica das potencialidades que a tecnologia pode trazer para construção e difusão do conhecimento. (BATISTA; ANDRADE, 2020, p.2)

O conhecimento e a tecnologia são considerados elementos indissociáveis. Por tanto, a escola precisa adequar-se a e acompanhar a sociedade tecnológica, pois possibilitará ao discente conhecer e adentrar no mundo das tecnologias, vivenciar novas experiências, suscitar a curiosidade, motivar-se para busca de novos conhecimentos que superam barreiras e ultrapassam limites e, na oportunidade, ajudar aos alunos no processo do saber e formação do indivíduo. (VIDAL; MIGUEL, 2020)

Entretanto, há barreiras que podem contribuir para que isso não se torne realidade, como por exemplo, resistência docente para desenvolver habilidades e técnicas necessárias sobre o uso das tecnologias digitais em sala de aula, equipamentos tecnológicos em condições precárias. Além desse aspecto, existem também: a falta de capacitação docentes para usar tecnologias de ensino, falta de investimento em infraestrutura nas escolas públicas para instalar a internet nos espaços escolares, inexistência de política de incentivo da escola para o uso de tecnologias, ausência de laboratório de informática nas escolas, entre outros.

Sabemos que as ferramentas tecnológicas têm intuito de ajudar e facilitar a forma de trabalho dentro e fora dos espaços escolares. No entanto, existem ainda professores que não enxergam com bons olhos as novas tecnológicas como instrumento transformador na sua prática pedagógica e decidem ou optam em continuar com as velhas práticas didáticas e metodológicas de ensinar. Essa rejeição muitas vezes se dá devido à falta de conhecimento por parte dos professores de como os aparelhos tecnológicos devem ser utilizados na sala de aula para garantir a praticidade durante o processo de ensino do professor e aprendizagem do aluno. Vale salientar que se as novas tecnologias não forem 
usadas, aproveitas para o processo educativo, torna-se difícil a inclusão digital na educação (LIMA; ANDRADE; DAMASCENO, s.d, n.p).

Além da resistência e falta de conhecimento já expressos anteriormente evidencia-se um empecilho: equipamentos tecnológicos em condições precárias. Pereira e Chagas (2014) realizaram uma pesquisa com professores de escolas públicas localizadas no município de Doverlândia/GO sobre as TICs e constataram que $13 \%$ dos professores consideram os computadores da escola em que atuam em boas condições, os demais encontram muitos problemas.

O que se justifica, segundo os autores pelo fato da péssima conexão com a internet, falta de manutenção das peças, vandalismo dos alunos nos laboratórios, já que nas escolas estaduais pesquisadas não existiam nenhum dinamizador responsável pelo ambiente. Por esses motivos, muitos professores sentiam-se, desanimados, desestimulados a desenvolver atividades que envolvem tecnologias, apesar de afirmar que consideram importante utilizar essas ferramentas.

Outro entrave que merece atenção, diz respeito à infraestrutura física das escolas. Estas se mostram precárias e isso prejudica o avanço e aplicabilidade das tecnologias educacionais nas escolas públicas brasileiras, principalmente as que se localizam em áreas rurais e de difícil acesso. Estas são escolas, na maioria delas fisicamente ruins, sem energia elétrica, sem estrutura adequada, por exemplo, o que impossibilita o uso de aparelhos eletrônicos. É, aí, que se aumenta ainda mais a desigualdade no acesso à internet e a própria educação à distância. Esta é infelizmente a realidade de muitos alunos antes mesmo da pandemia do novo Coronavírus - COVID 19 (SARS-CoV-2).

A inexistência de política de incentivo da escola para o uso de tecnologia é outro problema, sobretudo pela falta de apoio dos gestores e coordenadores escolares que acabam delimitando o processo de trabalho pedagógico em velhas práticas de ensino o que em muitos casos não ultrapassam as barreiras ainda existentes e acaba a deixar de lado outras estratégias que podem contribuir nitidamente ao processo ensino $x$ aprendizagem na educação básica.

Finalmente, existe também a ausência de laboratório de informática nas escolas. Sabemos que o processo de implantação da informática como instrumento pedagógico nas aulas, não é simples, principalmente quando se trata de laboratório com computadores que atendam a quantidade e as reais necessidades dos estudantes. Há certa dependência por parte do governo federal e/ou até mesmo municipal para repassar as verbas necessárias com o intuito de organizar/reformar o ambiente escolar e, também, comprar os aparelhos tecnológicos que comtemplem a todos de forma igualitária.

\subsection{Contribuições das TICs na educação}

Obviamente o computador e a internet transformaram os cenários mundiais. Sua introdução no processo de ensino e aprendizagem revelou-se como um desafio, mais também proporcionou o desenvolvimento de um ensino ainda mais interativo e em rede. O professor capacitado pode extrair dessa ferramenta tecnológica, meios que dinamizaram suas aulas, como a adoção de jogos, pesquisas didáticas, criação de blogs que enriquecem ainda mais sua prática docente (WIESE; SILVA, 2016).

Por sua vez os espaços escolares, mesmo que timidamente começaram a utilizar dessas ferramentas ainda pouco utilizadas, exigindo-se dos docentes o interesse pela prática na pesquisa digital, trabalhar em comunhão com seus alunos para construção do saber interativo por meio de estratégias digitais. 
Se por um lado a pandemia demonstrou fragilidades existentes em nosso Sistema Único de Saúde, por outro refletiu as dificuldades enfrentadas por milhares de gestores, coordenadores, professores, e alunos que foram desafiados a adentrar em um caminho ainda pouco utilizado priorizando as aulas remotas e a utilização de novas ferramentas tecnológicas.

Não obstante, as TICs foram e são fundamentais para dirimir as dificuldades ainda enfrentadas, tornaram o processo de ensino mais interativo, direcional e equânime. Infelizmente muitos alunos lidaram não somente pela impossibilidade de acesso em aulas remotas, mas também nas dificuldades econômicas de suas famílias (QUEIROZ, 2018).

Os alunos que frequentam a escola nos dias atuais foram imersos as tecnologias desde seu nascimento, a utilização de aparelhos celular para visualização de vídeos infantis, ou para tocar músicas são exemplos de como as tecnologias encontram-se diariamente em nosso cotidiano e garantem possibilidades que auxiliam no desenvolvimento didático e dinamizam as aulas em ambiente escolar (QUEIROZ, 2018).

Essas variedades de ferramentas tecnológicas sendo utilizada pelo professor durante o processo de ensino e aprendizagem atrai e motiva o aluno a querer estudar, construir e reconstruir saberes e, na oportunidade, compartilhar o conhecimento e informação com pessoas que se encontram ao seu redor. "Na sociedade da tecnologia da informação e comunicação nesses processos educacionais o docente já pode oportunizar ao aluno o contato, como ferramenta de envio de materiais didáticos e troca de mensagens." (BATISTA; ANDRADE, 2020, p.9). Além disso, pode usar chats, fóruns para debates e discussões de assuntos e/ou conteúdos que serão abordados na sala de aula pelo professor (BATISTA; ANDRADE, 2020).

As contribuições das TIC's no processo de ensino são inquestionáveis, porém é necessário o interesse público para possibilitar a todos internet móvel livre de oscilações, aparelhos tecnológicos que comportem os e-books e outros programas utilizados pelo docente que impulsionam para um aprendizado mais interativo e atraente.

A qualificação de professores na utilização de instrumentos tecnológicos também é necessária para que haja um processo de transformação do ensino aprendizagem, desmistificar o "eu não tenho prática no uso de tecnologias" ou até "já estou quase me aposentando" não são justificativas para não buscar novos métodos didáticos.

Não podemos deixar de lado tudo que o ensino anterior ao período pandêmico pode nos proporcionar, mas é preciso alinhar novos processos didáticos, avaliar o que é essencial, buscar novas estratégias e ampliar as práticas docentes, utilizando-se das novas tecnologias como meio para se chegar ao objetivo primordial da educação que é a aprendizagem do aluno.

Neste sentido, é válido destacar algumas pesquisas empíricas brasileiras efetivados no período de 2016 a 2021 conforme expressas anteriormente que investigaram sobre as contribuições das TIC's na prática pedagógica do professor, ou seja, especificamente na sala de aula.

Em sua pesquisa de dissertação de mestrado Pereira (2016) constatou que as aulas ministradas pelos professores que foram baseadas em animações interativas ajudaram a dinamizar o ensino. Favoreceu também, a aprendizagem significativa dos conteúdos propostos. Permitiu aos alunos vivenciar e experimentar novas formas de aprender a disciplina citologia em um contexto significativo e na 
condição de sujeitos protagonistas de sua aprendizagem. Além disso, possibilitou a motivação e o desenvolvimento de sua aprendizagem.

Ao realizar uma pesquisa em uma turma do $5^{0}$ ano do Ensino Fundamental I dos Anos Iniciais em uma Escola Municipal no Vale do Paraíba/SP, Cursino (2017) evidenciou que o uso das tecnologias em projetos educacionais permite conceber o ensino e aprendizagem mais dinâmico, interativo e colaborativo. Este feito, só foi possível pela aplicação de atividades baseadas em projetos que integram os objetos do conhecimento (conteúdo) sobre Meio Ambiente aos recursos tecnológicos disponíveis na escola.

Consoante ao disposto anteriormente, Valadares (2019) desenvolveu uma pesquisa com o intuito de observar as possíveis contribuições das "Histórias em Quadrinhos Digitais" no aprimoramento das competências de leitura, escrita, compreensão e interpretação de texto por meio do uso do celular, vídeos, blog em uma turma de vinte e nove alunos, do $6^{\circ}$ ano do Ensino Fundamental de uma escola do Estado de Sergipe.

Os resultados mostraram que houve melhorias nas competências de leitura e escrita e, que, os alunos foram submetidos a diferentes tipos de letramentos, (principalmente, ao letramento digital), essenciais para transformar o aluno em um verdadeiro cidadão, que esteja preocupado com os problemas sociais, como por exemplo, as questões ambientais, além de ter discernimento crítico, ser criativo, atuante e transformador da realidade presente no seio social (VALADARES, 2019).

Com o intuito de compreender os efeitos gerados pela política pública de utilização de tablets no ensino fundamental nos indicadores de desempenho escolar, Hammes (2016), evidenciou efeitos positivos no desempenho escolar dos alunos apesar de reconhecer a existência de problemas de ordem política e técnica durante sua implementação.

Em sua pesquisa investigativa, Nóbrega (2018) desenvolveu uma experiência de formação continuada de professores em uma escola na cidade de Patos-PB, com o Google for Education como ambiente virtual de ensino-aprendizagem e instrumento didático pedagógico. Evidenciou que esse instrumento é capaz de ajudar o docente a melhorar a sua prática pedagógica, aperfeiçoando o conhecimento e manuseio do dispositivo tecnológico em sala de aula.

Ao realizar uma pesquisa com o objetivo de compreender a utilização da internet e suas interfaces pelos professores de Biologia em sala de aula, numa escola da rede estadual Nascimento (2016) comprovou que as interfaces representam para os professores uma nova estratégia de ensino e que seu uso dinamiza as aulas despertando nos alunos a criatividade, imaginação e possui às vezes uma linguagem de fácil entendimento.

Notou-se também a existência de outras potencialidades que passaram a ser mais exploradas nas aulas, conferindo uma mudança no processo de ensino e aprendizagem e que a usabilidade da internet como instrumento pedagógico permite que o professor vislumbre mudanças significativas na melhoria da qualidade de ensino.

Ao investigar como ocorre o processo de ensino e aprendizagem em salas de aula em que as tecnologias se fazem presentes Pesker (2018) contatou a existência de mobilidade no ambiente de aprendizagem; agilidade e otimização do tempo das aulas; variedade de recursos, viabilizando a aprendizagem por meio de jogos, simuladores, imagens e aplicativos que possibilitam aprender 0 conteúdo de formas diferentes e lúdicas. 
Em sua pesquisa sobre o uso de laboratórios on-line (remoto e virtual) integrados a Sequências Didáticas Investigativas (SDI), que disponibilizados em Ambiente Virtual de Aprendizagem (AVA), em aulas de biologia para o ensino médio, Santos (2018). Constatou que o uso dessa ferramenta contribui para a motivação do estudo da biologia e proporciona melhor compreensão dos conteúdos, tornando a aprendizagem mais eficaz e significativa.

O estudo de Fialho (2016), evidenciou como o uso das TICs influência e entrecruza olhares sobre os processos de aprendizagem na atualidade, contextualizando problemas e possibilitando a ressignificação dos conhecimentos no plano da ação escolar. Em sua pesquisa ele teve a possibilidade analisou o impacto que as tecnologias podem causar no cotidiano de educandos do Ensino Fundamental e quais perspectivas precisam ser utilizadas para aproximar professores e alunos neste mundo digital.

Na pesquisa de Santos, (2018) relatou o uso de dispositivos móveis durante o ensino-aprendizagem no estudo das ondas. A análise primária dos dados gerou medidas de tendência que remetem à conclusão de que o uso desses dispositivos em sala de aula, e fora dela, no contexto atual, facilitam a aprendizagem dos discentes no estudo de ondulatória no Ensino Médio. Além disso, tornam a sala de aula mais atraente e educam para uma cultura digital. $O$ atendimento online reaproxima o docente dos discentes rompendo a dimensão do tempo e do espaço, ratifica o papel da escola na sociedade contemporânea e sua relação com a comunidade.

Ao contribuir com tais comentários Silva (2017) com o apoio da Etnomatemática, já havia demonstrado em seu estudo evidências de que o e-book e o blog encontram-se imbuídos no propósito da interação entre o saber docente e o saber escolar, e, nesse contexto tecnológico, apresentou dicas e sugestões para que o professor utilize, na disciplina de Matemática, recursos tecnológicos que facilitarão a explanação de determinado conteúdo.

\section{CONSIDERAÇÕES FINAIS}

Os estudos analisados trouxeram um panorama do uso das TICs no ambiente escolar e evidenciaram que a utilização de novas tecnologias no ensino revela-se como um desafio a ser superado. Cabe aqui romper paradigmas pessoais e ou até didático x metodológico para que se possa tratar do uso das novas tecnologias como instrumentos transformadores do ensino aprendizagem, ultrapassando-se 0 medo e as inseguranças quanto a sua utilização.

Nesse momento, percebe-se o quão as tecnologias foram e são fundamentais para modificar e/ou até transformar a realidade, as aulas remotas demonstraram a significância do uso dessas ferramentas e sua importância na nova forma de aprender e ensinar.

Os professores e alunos foram surpreendidos, neste momento pandêmico mais puderam vislumbrar e ultrapassaram o ambiente físico em sala de aula e adentraram no meio digital, utilizaram e utilizam de plataformas que não deixaram de lado o vínculo, o apoio mútuo e a aprendizagem cooperativa e em rede.

Novos estudos sobre a temática devem ser elaborados com intuito de sanar os motivos pelos quais ainda se nota empecilhos que atrapalham a materialização do uso de tecnologias em sala de aula cujo intuito seja gerar discussões significativas quanto à necessidade de adoção de novas estratégias didáticas de ensino aprendizagem. Para isso, diretores, coordenadores, professores e alunos são 
fundamentais, pois embora possuam atribuições distintas no que concerne à aprendizagem ambos se interligam e interagem nos caminhos da construção do saber.

Salienta-se aqui, que durante a construção deste trabalho foram encontradas algumas fragilidades bem como, por exemplo, a escassez de pesquisas empíricas brasileiras de acordo ao objeto de estudo na base de dados escolhida conforme já explicitado no texto. Isso dificultou trazer mais informações acerca das contribuições das novas tecnologias para o ensino e aprendizagem.

A proposta deste referido artigo promoverá contribuições para a formação do professor por garantir habilidades essenciais que geram segurança quanto à materialização das TIC's nos espaços escolares. Ajudará também aos mesmos a romperem barreiras, superar desafios e limites em relação a inserção das novas tecnologias durante o processo de ensino e aprendizagem. Por meio desta pesquisa, poderá dá condições ao professor para que ele aprimore sua prática pedagógica, expandindo sua visão sobre os processos de aprendizagem e a necessidade de mudanças das velhas práticas pedagógicas.

A pesquisa contribuirá também para o conhecimento científico, pois pretende abrir espaços com discussões mais profundas acerca das novas tecnologias na educação. Permitirá aprimorar os conhecimentos epistemológicos em torno do objeto de estudo. Possibilitará debates acerca de políticas públicas e práticas de tecnologias na educação voltadas para a melhoria da informatização das instituições escolares. Por fim, ajudará a fortalecer as discussões em linhas de pesquisa acadêmicas que versam sobre tecnologia aplicada na educação.

\section{REFERÊNCIAS}

BRASIL. Ministério da Educação. Parâmetros Curriculares Nacionais: Ensino Médio. Brasília: MEC/SEF, p.1-23, 2000.

BARDIN, Laurence. Análise de conteúdo. 3. ed. Lisboa: Edições 70, 2004.

BRIGHENTE, Miriam Furlan. MESQUIDA, Peri. Paulo Freire: da denúncia da educação bancária ao anúncio de uma pedagogia libertadora. Pro-Posições, Campinas-SP, v. 27, n. 1, p. 155- 177, Jan/Abr, 2016.

BATISTA, Cecilia Godinho. ANDRADE, Paulo César de Resende. A inserção das Novas Tecnologias de Informação e Comunicação (NTICs) nos processos de ensino-aprendizagem. Revista Vozes dos Vales - UFVJM - MG - Brasil - No 18 - Ano IX - 10/2020. Disponível em http://site.ufvjm.edu.br/revistamultidisciplinar/files/2020/10/Paulo.pdf. Acesso em 05 de Dez. 2020.

CAMILLO, Cíntia Moralles; MEDEIROS, Liziany Muller. Educação do campo e suas práticas educativas: a tecnologia em prol da formação de professores. In: Simpósio de Tecnologias e Educação a Distância no Ensino Superior, 2018.

CURSINO, André Geraldo. Contribuições das Tecnologias para uma aprendizagem significativa e o desenvolvimento de projeto no ensino fundamental I. Dissertação (Mestrado). Universidade de São Paulo, São Paulo. 2017.

FERREIRA, Rafael Antunes. Utilização de animação interativas aliada à teoria da aprendizagem significativa: um recurso no ensino de Biologia Celular. Dissertação (Mestrado). Universidade Federal do Espírito Santo, Espírito Santo. 2016. 
FIALHO, Bruno Passos. Tecnologias de Informação e Comunicação na escola: Contradições e elementos de aprendizagem. 2016. Dissertação (Mestrado). Centro Universitário La Salle. Canoas. 2016.

GIL, Antônio. Carlos. Como elaborar projetos de pesquisa. 5. ed. São Paulo: Atlas, 2018.

GONÇALVES, Jonas. Rodrigo. et al. A evolução da tecnologia na educação. Revista Processus de Estudos de Gestão Jurídicos e Financeiros, v. 10, n. 37, p. 21-34, Jan/Mar, 2019

HAMMES, Maicon Rafael. Uso de tecnologias de informação no ensino fundamental e o desempenho escolar no sul do Brasil: o caso do tablet no município Doutor Maurício Cardoso. 2016. Dissertação (Mestrado) - Universidade Estadual do Rio Grande do Sul, Rio Grande do Sul. 2016.

LIMA, Jeane de Oliveira. ANDRADE, Maria Nascimento de. DAMASCENO, Rogério José de Almeida. A resistência do professor diante das novas tecnologias. Disponível em:

https://meuartigo.brasilescola.uol.com.br/educacao/a-resistencia-professor-diante-das-novastecnologias.htm. Acesso em 02 de out.2021.

MORAN, José Manuel. Ensino híbrido: equilíbrio entre a aprendizagem individual e a grupal. In: Simpósio Hipertexto e Tecnologias na Educação, 60, Recife, 2015a. Anais. Universidade Federal de Pernambuco, 2015.

NASCIMENTO, Emerson dos Santos. A utilização da internet nas aulas de Biologia: estudo de caso em uma escola da rede estadual de Alagoas. Dissertação (Mestrado) - Universidade Federal de Sergipe, Sergipe. 2016.

NÓBREGA, Josley Maycon de Sousa. Google for education na formação continuada de professores do ensino médio em Patos-PB. Dissertação (Mestrado) - Universidade Estadual da Paraíba, Paraíba. 2018.

PEREIRA. Stelamara Souza. CHAGAS, Flomar Ambrosina Oliveira. As tecnologias na prática docente: obstáculos ou caminhos? Disponível em: http://revistas.ifg.edu.br/semlic/article/download/463/258. Acesso em 02 de out. 2021.

PEREIRA, Paula Virginia Alves. O uso da tecnologia na educação infantil: contribuições e implicações pedagógicas. Monografia (Trabalho de Conclusão de Curso em Mídias na Educação) Universidade Federal de São João Del-Rei. São Paulo, 2019

PESKER, Eleine Silva. Educação e tecnologia: o uso dos dispositivos móveis como auxílio no processo de ensino e aprendizagem em sala de aula. Dissertação (Mestrado) - Pontifícia Universidade Católica de Minas Gerais, Minas Gerais, 2018.

QUEIROZ, Joelma de Pontes Silveira. O impacto do uso da tecnologia como ferramenta pedagógica na sala de aula. Disponível em:

https://cietenped.ufscar.br/submissao/index.php/2018/article/download/102/109. Acesso em: 05 de Dez. 2021.

SANTOS, Reginaldo Almeida dos. Tecnologia digital e dispositivos móveis como facilitadores do ensino-aprendizagem de ondulatória no ensino médio. Dissertação (Mestrado) - Universidade Federal do Ceará, Fortaleza, 2018. 
SANTOS, Aline Coêlho dos. Integração de Tecnologia na Educação Básica: Um estudo de caso nas aulas de Biologia utilizando laboratórios on-line. Dissertação (Mestrado em Tecnologias da Informação e Comunicação) - Universidade Federal de Santa Catariana, Santa Catarina: 2018.

SANTO, Sandra Aparecida Cruz do Espírito. MOURA, Giovana Cristina de. SILVA, Joelma Tavares da. O uso da tecnologia na educação: Perspectivas e entraves. Revista Científica Multidisciplinar Núcleo do Conhecimento. Ano 05, Ed. 01, Vol. 04, pp. 31-45. Jan de 2020.

SILVA, Claci Clair Röpke da. A tecnologia como estratégia Etnomatemática: Um estudo de caso sobre o uso das tecnologias no ensino da Matemática no sexto ano do Ensino FundamentalAnápolis. Dissertação (Mestrado) - Universidade Estadual de Goiás. 2017.

SCHUHMACHER, Vera Rejane Niedersberg. FILHO, José de Pinho Alves. SCHUHMACHER, Elcio. As barreiras da prática docente no uso das tecnologias de informação e comunicação. Revista Ciênc. Educ., Bauru, v. 23, n. 3, p. 563-576, 2017. Disponível em: http://www.scielo.br/pdf/ciedu/v23n3/1516-7313-ciedu-23-03-0563.pdf. Acesso em 05 de Dez. 2017.

VALADARES, Nice Vânia Machado Rodrigues. Leitura e produção de histórias em quadrinhos digitais: uma proposta de uso do smartphone. Dissertação (Mestrado em Letras) - Universidade Federal de Sergipe, Aracaju, 2019.

VIDAL, Altemar Santos; MIGUEL, Joelson Rodrigues. As Tecnologias Digitais na Educação Contemporânea. Rev.Mult. Psic, n.50, vol.14, Maio/2020

WIESE, Andréia Faxina. SILVA, Marcelo José da. Possibilidades e limites de uso das tecnologias digitais na escola pública de ensino fundamental. Disponível em: https://www.unicesumar.edu.br/ /mostra-2016/wpcontent/uploads/sites/154/2017/01/andreia_faxina_wiese.pdf. Acesso em 01 de Out. 2021.

Submissão: 11/10/2021

Aceito: 18/01/2022 